\title{
SEBARAN SUHU DAN SALINITAS DI TELUK MANADO
}

\author{
(Distribution of temperature and salinity in Manado Bay)
}

\author{
Patrice NI Kalangi ${ }^{1}$, Anselun Mandagi ${ }^{1,3}$, KWA Masengi ${ }^{1}$, \\ Alfret Luasunaung ${ }^{1}$, FPT Pangalila ${ }^{1}$, Masamitsu Iwata ${ }^{2}$ \\ ${ }^{1}$ Fakultas Perikanan dan Ilmu Kelautan Universitas Sam Ratulangi, Manado, Sulawesi Utara. \\ ${ }^{2}$ Aquamarine Fukushima, Marine Science Museum, Iwaki, Fukushima, Japan. 9718101. \\ 3 Sekarang di PT Haji La Tunrung AMC, Banjarmasin.
}

\begin{abstract}
Penelitian ini bertujuan untuk mendeskripsikan sebaran suhu dan salinitas di Teluk Manado, Sulawesi Utara. Pengukuran suhu dan salinitas secara vertikal dilakukan di delapan tempat di teluk. Profil vertikal suhu dan salinitas memperlihatkan keberadaan pelapisan kolom air. Secara horizontal, kontur suhu dan salinitas di permukaan memiliki dua "kolam" massa air, yakni kolam yang bersuhu tinggi tapi bersalinitas rendah di bagian timur teluk dan kolam yang bersuhu rendah tapi bersaliritas tinggi di bagian barat teluk. Pada lapisan dalam, kontur suhu dan salinitas cenderung sejajardengan garis pantai bagian timur.

Kata kunci: suhu, salinitas, air sungai, Teluk Manado.

The objective of this research is to describe temperature and salinity distribution in Manado Bay, North Sulawesi. The vertical measurements of temperature and sabinity were done at eight locations in the bay. The vertical profiles of temperature and salinify stows the existence of water column stratification. Horizontally, temperature and salinity contours of the surface layer have two pools, i.e. a pool of high temperature but low salinity in the eastern part of the bay and a pool of low temperature but high salinity in the western part of bay. In a deeper layer, the contours of temperature and salinity tend to be parallel to eastern coastline.
\end{abstract}

Keywords: temperature, salinity, river discharge, Manddo Bay.

\section{PENDAHULUAN}

Suhu dan salinitas merupakan faktor oseanografi yang mudah diukur tetapi berpetán penting dalam proses-proses fisika, kimia maupun biologi di laut, seperti dalam proses percampuran, konsentrasi oksigen terlarut dan penyebaran organisme laut (Knauss, 1997; Laevastu dan Hayes, 1982). Oleh sebab itu informasi sebaran spastal dan temporal suhu dan salinitas menjadi sangat berharga.

Kisaran suhurdi laut adalah $-2-35^{\circ} \mathrm{C}$. Knaus (1997) menjelaskan belhwa suhu suatu perairan dipengaruhi oleh posisi matahari, letak geografis, musim dan kondisi atmosfir. Faktor lain yang juga mempengarthí suhu perairan adalah batimetri (Xie dkk., 2002) dan pegunungan di daratan (Kitoh, 2001).

Secara vertikal, profil suhu di suatu perairan dalam terbagi dalam tiga lapisan utama (Garrison, 2004). Pertama, lapisan permukaan yang tercampur sempurna (mixed layer). Lapisan ini hangat dan memiliki gradien suhu dengan kedalaman yang kecil. Kedua, lapisan termoklin (thermocline layer) yakni lapisan dengan penurunan suhu yang mencolok atau lapisan yang memiliki gradien suhu yang besar. Gradien suhu pada lapisan ini sekitar $0,1^{\circ} \mathrm{C}$ per meter (Nontji, 1987). Terakhir, lapisan dalam (deep
- layer) yang memiliki suhu yang rendah tetapi relatif konstan pada $4^{\circ} \mathrm{C}$.

Sebaran horizontal salinitas dipengaruhi oleh pola sirkulasi air, penguapan, curah hujan dan air sungai (Fong dan Geyer, 2001; Kalangi, 2008; Kalangi et.al., 2012). Pengaruh air sungai membuat variasi salinitas di perairan pantai lebih besar dibanding perairan laut lepas (Garrison, 2004; Hickey et. al., 1998). Kisaran salinitas di perairan pantai dapat berkisar dari $0-33$ tergantung pada volume air sungai yang dialirkan.

Secara vertikal nilai salinitas air laut akan semakin besar dengan bertambahnya kedalaman tetapi perubahan ini tidak linear. Kolom perairan dapat dibagi atas tiga lapisan, yaitu a) lapisan permukaan yang tercampur baik, ketebalan 50-100 m, dan memiliki nilai salinitas yang seragam; b) lapisan dengan perubahan salinitas yang relatif besar, yang disebut lapisan haloklin; dan c) lapisan dengan nilai salinitas yang seragam dan berada di bawah lapisan haloklin hingga ke lapisan dasar laut (Garrison, 2004). Berbeda dengan suhu, salinitas yang lebih tinggi umumnya berada pada lapisan dalam.

Gambaran mengenai suhu dan salinitas di perairan Teluk Manado Provinsi Sulawesi Utara masih sangat terbatas dan umumnya tidak dipubli- 
kasikan. Hal ini akan membatasi pemahaman lebih lanjut, misalnya terhadap proses pergerakan massa air dan pengaruhnya terhadap ekosistem. Artikel ini akan memberikan gambaran distribusi suhu dan salinitas secara horizontal dan vertikal di perairan Teluk Manado.

\section{METODE PENELITIAN}

Pengukuran suhu dan salinitas dilakukan pada tanggal 2 September 2010 dari atas kapal penelitian Asalam mulai pukul 09.00-14.00 WITA. Pengukuran dilakukan di delapan stasiun yang tersebar mulai dari daerah muara Kali Jengki kemudian ke arah laut, pantai Malalayang dan pantai Kalasei. Lokasi dan stasiun pengumpulan data ditampilkan pada Gambar 1.

Peralatan utama yang digunakan dalam pengumpulan data ini adalah Alec CTD ASTD 687 untuk mengukur suhu dan salinitas, fishing rod dengan winch merek Shimono untuk menaik-turunkan CTD, dan Garmin GPS genggam untuk menentukan posisi pengukuran. Pada stasiun yang telah ditetapkan, CTD yang telah diikatkan pada fishing rod diturunkan secara perlahan sampai pada kedalaman yang diinginkan kemudian diangkat kembali. Data yang digunakan adalah data yang dikumpulkan CTD pada saat turun (Kalangi et.al., 2012).

Suhu dan salinitas di setiap stasiun digambarkan terhadap kedalaman. Selanjutnya hasil $\widehat{p}$ e ngukuran di beberapa stasiun digabung untuk hembuat peta kontur dengan menggunakan perangkat lunak Matlab.

\section{HASIL PENELITTAN}

Kedalaman pengukuran uptuk setiap stasiun berbeda-beda dan berkisar antara 110-492 m. Pengukuran tidak dilakukan sampai pada dasar perairan dan kedalaman pengúkuran yang dangkal dilakukan di dekat pantai.

\section{Suhu}

Profil suhu pada Gambar 2 memperlihat adanya tiga lapisan massa air sesuai yang dijelaskan oleb Garrison (2004). Suhu rata-rata pada kedalaman $1,50,100$ dan $200 \mathrm{~m}$ berturu-turut adalah 30,17 , $28,18,23,41$, dan $15,76^{\circ} \mathrm{C}$. Pada beberapa stasiun, ketebalan lapisan permukaan yang relatif homogen berbeda secara mencolok. Pada stasiun-stasiun lepas pantai, lapisan permukaan ini sampai pada kedalaman sekitar $50 \mathrm{~m}$, sedangkan pada stasiun-stasiun di bagian pinggiran teluk, lapisan permukaan mencapai $100 \mathrm{~m}$. Perbedaan ketebalan ini dapat disebabkan oleh lebih efektifnya proses percampuran massa air yang disebabkan oleh angin dan/atau pasang

surut di daerah pantai (Geyer dan Signell, 1992; van de Kreeke dan Robaczewska, 1989). Angin yang bertiup di atas permukaan laut akan memberikan gaya friksi terhadap air laut yang akan menyebabkan pergerakan massa air dan terjadinya proses pengadukan air laut. Semakin besar kecepatan angin yang berhembus di atas permukaan laut semakin kuat pengadukan massa air yang selanjutnya akan meningkatkan ketebalan lapisan homogen. Sedangkan pasang surut akan mempengaruhi proses pengadukan di bagian dasar perairan, khususnya di perairan pantai.

4

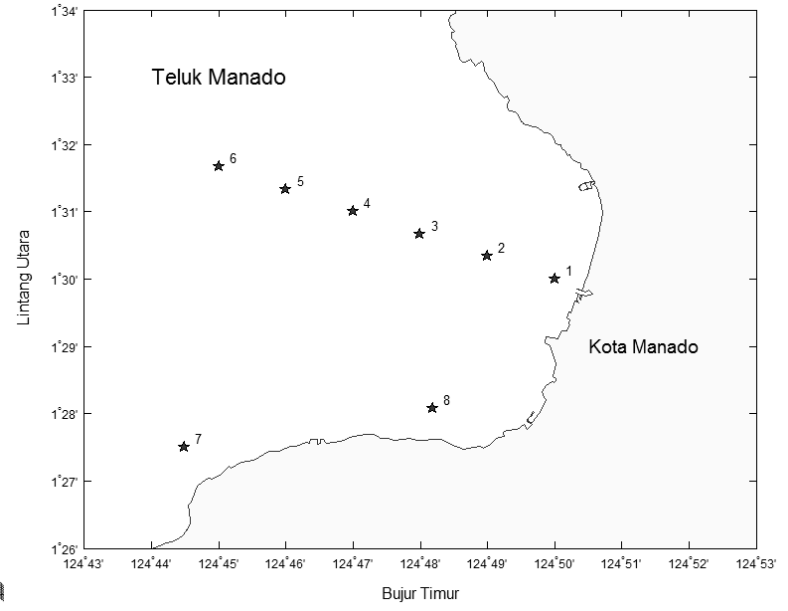

\section{Gar}

\section{Figure 1. Data collection locations in the Bay of Manado, North Sulawesi.}

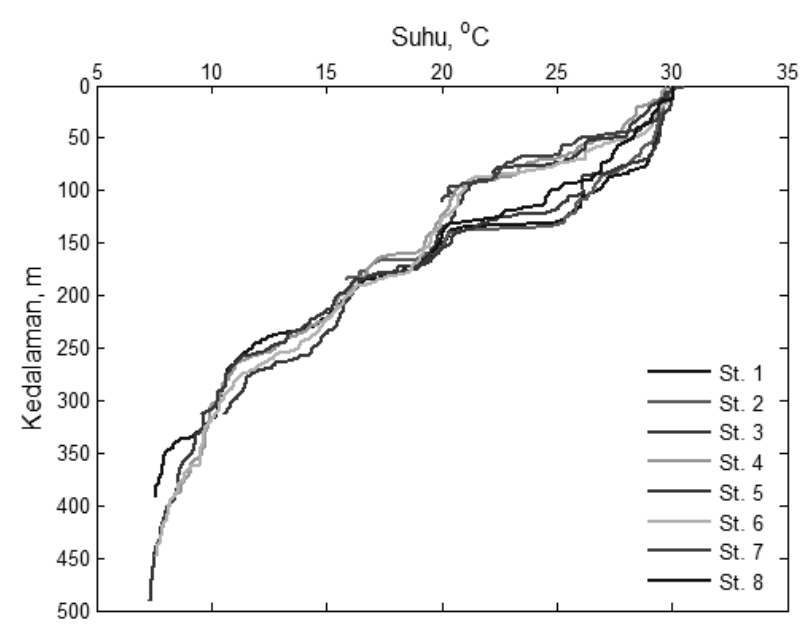

Gambar 2. Profil vertikal suhu.

Figure 2. Vertical temperature profile.

Lapisan termoklin berada pada kedalaman dari $100 \mathrm{~m}$ sampai $400 \mathrm{~m}$. Suhu rata-rata pada kedalaman-kedalaman tersebut berturut-turut adalah $24,50^{\circ} \mathrm{C}$ dan $7,50^{\circ} \mathrm{C}$; dengan demikian gradien penurunan suhu pada lapisan ini sekitar $0,06{ }^{\circ} \mathrm{C}$ per meter. Nilai ini lebih kecil dibanding nilai yang diberikan oleh Nontji (1987). Namun demikian gradien suhu pada suatu kedalaman tertentu dapat men- 
capai $1,8^{\circ} \mathrm{C}$ per meter. Gambar 3 (panel kiri) memetakan gradien suhu pada setiap kedalaman. Terlihat bahwa gradien yang besar terjadi pada kedalaman mulai dari $50 \mathrm{~m}$ sampai $400 \mathrm{~m}$, yakni pada lapisan termoklin.
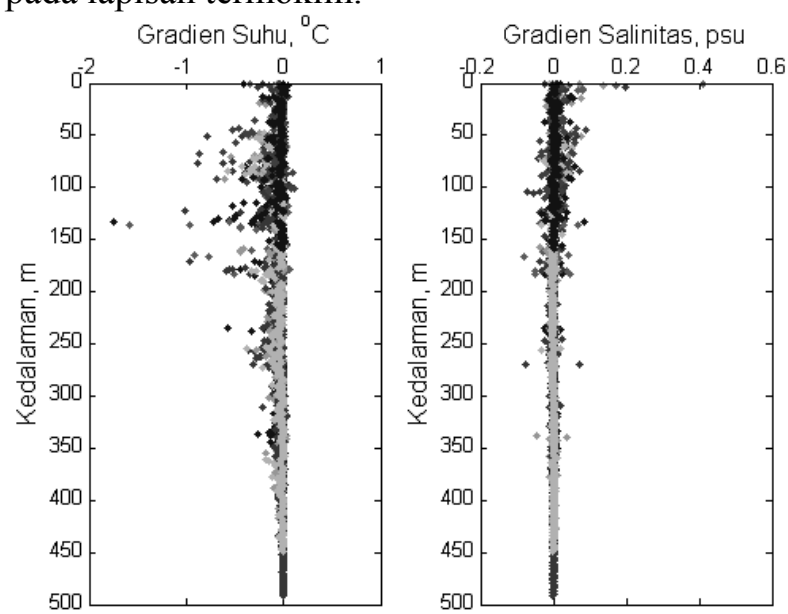

Gambar 3. Gradien suhu dan salinitas di delapan stasiun.

Figure 3. Gradients of temperature and salinity in eight stations.

Secara horizontal, suhu rata-rata pada kedalaman $1 \mathrm{~m}$ adalah $30,17^{\circ} \mathrm{C}$ dan suhu tertinggi terukur pada stasiun 2 (dekat daratan) sebesar $30,54^{\circ} \mathrm{C}$. Nilai suhu air maksimum diukur pada siang hari sekitar jam 13:59 WITA dan dalam kondisi air laut sedang bergerak surut. Untuk mengurangi pengarah perbedaan jam pengukuran terhadap variasi suhu, maka suhu dan salinitas lapisan permukaan diambil rata-rata dari permukaan $(1 \mathrm{~m})$ sampai pada kedalaman $45 \mathrm{~m}$.

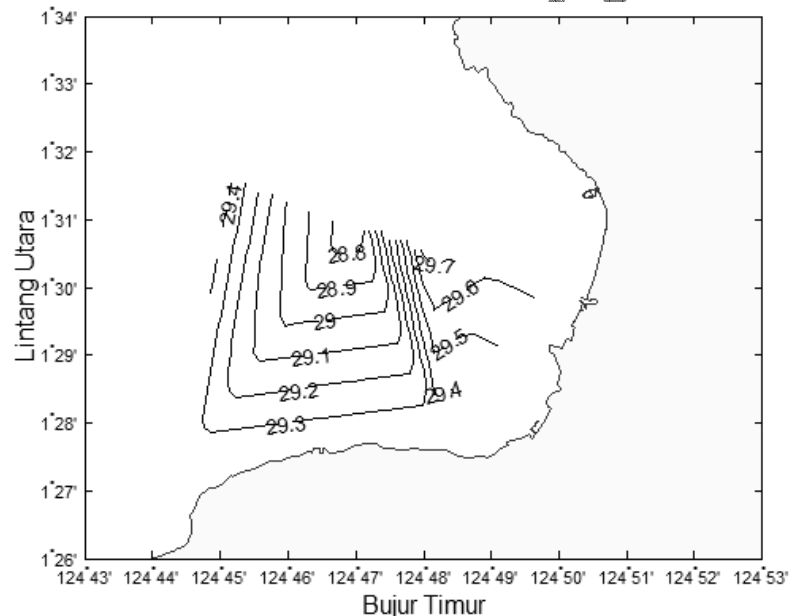

Gambar 4. Sebaran horizontal suhu permukaan (kedalaman 1-45 m).

Figure 4. Horizontal distribution of surface temperature (1-45 m depth).

Sebaran suhu horizontal di permukaan berkisar antara $28,0-29,7^{\circ} \mathrm{C}$ (Gambar 4), sedangkan pada kedalaman $100 \mathrm{~m}$ diperoleh nilai berkisar an- tara $20-25^{\circ} \mathrm{C}$ (Gambar 5). Pada lapisan permukaan suhu tertinggi berada di daerah pantai bagian timur dan suhu terendah cenderung berada pada bagian lepas pantai. Kontur suhu memperlihatkan keberadaan dua "kolam" air dengan pusat yang bersuhu tinggi di bagian timur teluk dan bersuhu rendah di bagian barat teluk. Hal ini dapat mengindikasikan bahwa pada lapisan permukaan terjadi sirkulasi horizontal. Sirkulasi ini dapat ditimbulkan oleh angin, arus pasang surut, dan perbedaan gradien tekanan karena masukan air sungai (Geyer, 1997; Geyer et. al., 2000). Pada lapisan kedalaman $100 \mathrm{~m}$, profil suhu cenderung sejajar dengan garis pantair timur tetapi dengan suhu semakin rendah ke ærah lepas pantai.

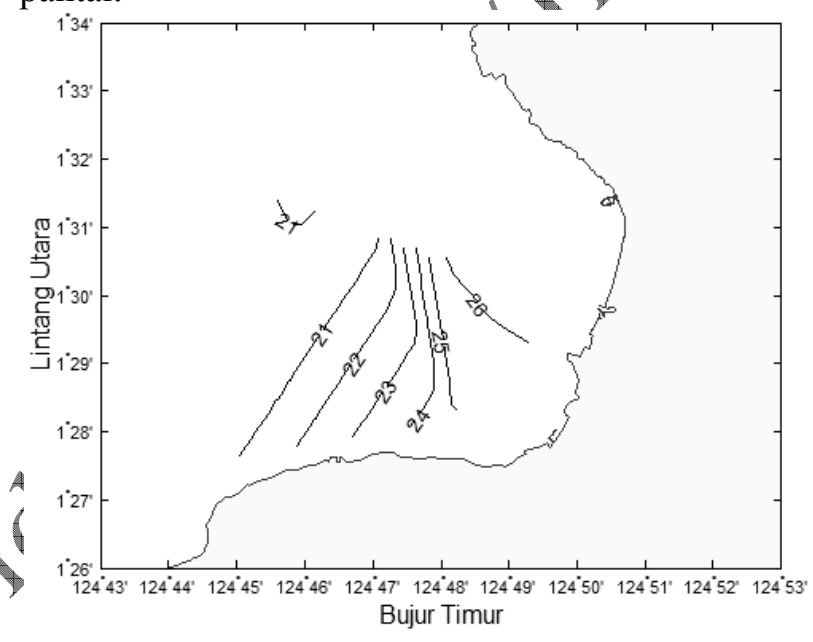

Gambar 5. Sebaran horizontal suhu pada kedalaman $100 \mathrm{~m}$.

Figure 5. Horizontal distribution of temperature at a depth of $100 \mathrm{~m}$.

\section{Salinitas}

Secara vertikal salinitas umumnya meningkat dengan bertambahnya kedalaman (Gambar 6). Nilai salintas rata-rata pada kedalaman $1,50,100$ dan $200 \mathrm{~m}$ secara berturut adalah 33,78, 34,09, 34,59, dan 34,54 .

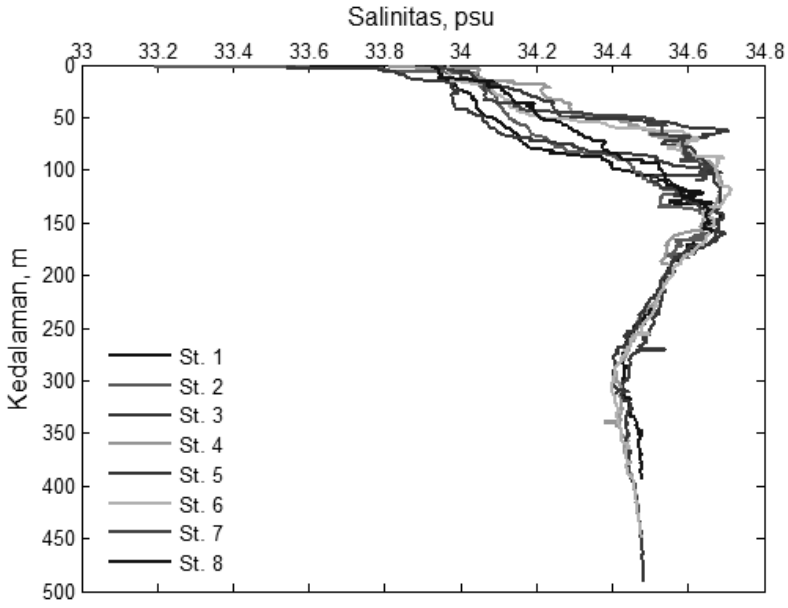

Gambar 6. Profil vertikal salinitas.

Figure 6. Vertical profiles of salinity. 
Pelapisan kolom air berdasarkan salinitas ini tidak sejelas pada suhu. Akan tetapi bila diperhatikan secara saksama, kedalaman lapisan permukaan mencapai 100 m seperti pada suhu. Pada kedalaman dari $100 \mathrm{~m}$ sampai $150 \mathrm{~m}$, salinitas meningkat lebih tajam. Lapisan ini dikenal sebagai lapisan haloklin. Di bawah lapisan ini, salinitas menurun secara cepat dengan bertambahnya kedalaman dan mulai pada kedalaman $300 \mathrm{~m}$ salinitas kembali meningkat secara perlahan. Fenomena tingginya Salinitas pada kedalaman 150 m mungkin disebabkan oleh intrusi air laut lepas yang bersalinitas sangat tinggi (juga lebih tinggi dari lapisan dalam di setiap stasiun) ke bawah lapisan permukaan yang bersalinitas rendah.

Gambar 3 (panel kanan) memberikan gradien salinitas pada setiap meter kedalaman. Pada lapisan halokin gradien lebih kecil dari 0,2. Gradien salinitas yang besar terjadi pada kedalaman antara 50 dan $250 \mathrm{~m}$. Akan tetapi, gradien yang besar juga terjadi di permukaan. Hal ini disebabkan oleh adanya input air tawar dari sungai-sungai di perimeter Teluk Manado.

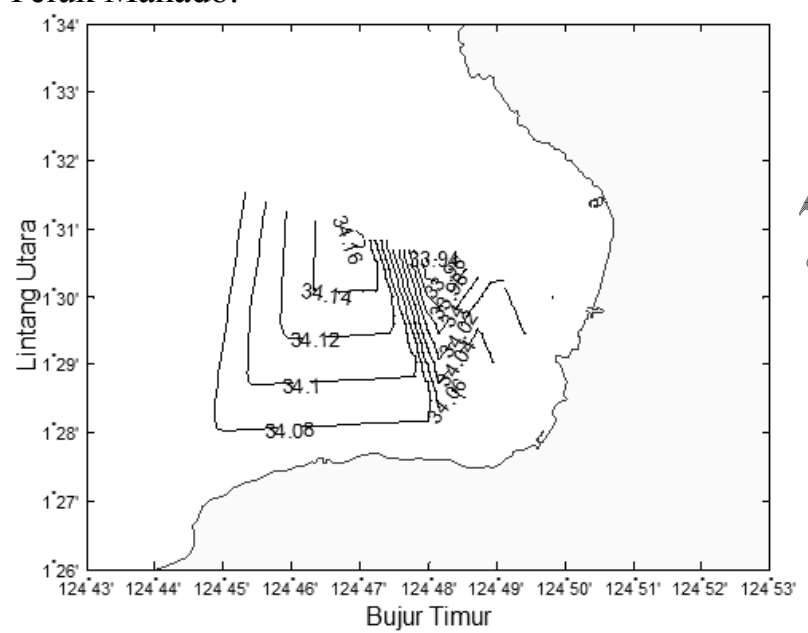

Gambar 7. Sebaran horizontal salinitas permukaan'(kedalaman 1-45 m).

Figure 7. Horizontal distribution of surface salinity (1-45 m depth).

Secara horizontal, kisaran salinitas pada lapisan permukaan adalah 33,94-34,16 (Gambar 7), sedangkan kisaran salinitas pada kedalaman $100 \mathrm{~m}$ adalab 34,44-34,66 (Gambar 8). Salinitas tinggi pada lapisan permukaan umumnya dijumpai di perairan jauh dari pantai, sebaliknya salinitas yang lebih rendah berada pada perairan dekat daratan. Nilai salinitas minimum di lapisan pemukaan terjadi di stasiun 2 sebesar 33,19. Stasiun ini sangat dekat dengan muara Kali Jengki sehingga pengaruh air sungai sangat kentara. Campuran air sungai memiliki densitas yang lebih rendah, oleh sebab itu massa air ini akan berada di atas massa air bersalinitas tinggi (Knauss, 1997).

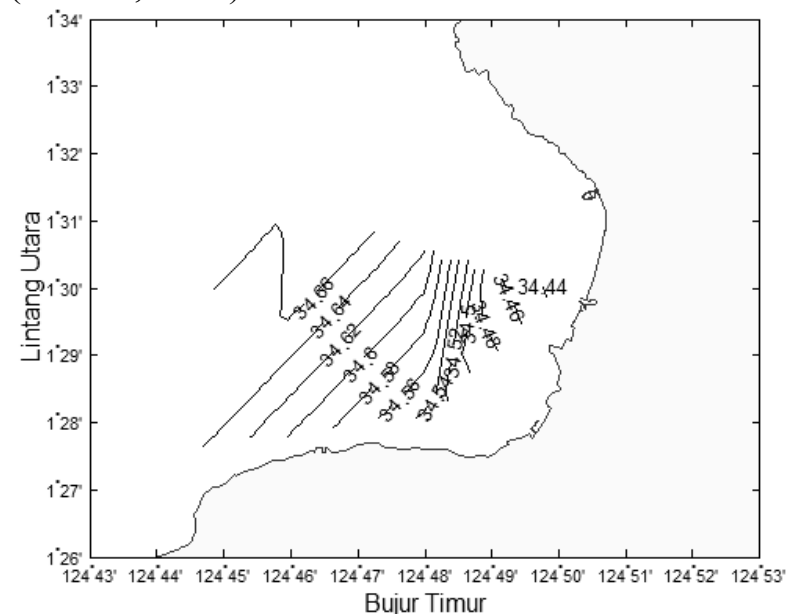

Gambar 8. Sebaran horizontal salinitas pada kedalaman $100 \mathrm{~m}$

Figure 8. Horizontal distribution of salinity at $100 \mathrm{~m}$ depth.

Seperti pada suhu, kontur salinitas memperlihatkan dua kølam air di lapisan permukaan, yakni kolam air betsalinitas tinggi di bagian timur dan kolam air bersalinitas tinggi di bagian barat. Fitur yang mirip juga teramati di muara Sungai Sario saat debit sungai' rendah (Kalangi, 2008). Hal ini dapat disebabkan oleh arus pasang surut yang memotong atau memodifikasi arah aliran air sungai (Lewis, 1997).

- Di daerah pinggiran pantai, arus pasang surut ini cenderung tidak menentu (chaotic) (Tulungen et.al., 2012) sehingga massa air bersalinitas rendah membentuk patches yang membuat percampuran dengan massa air bersalinitas tinggi berlangsung lebih cepat (Knauss, 1997). Pada lapisan kedalaman 100 m, seperti pada suhu, profil salintas cenderung sejajar dengan garis pantai timur tetapi semakin tinggi ke arah lepas pantai.

\section{KESIMPULAN}

Suhu permukaan perairan Teluk Manado antara $28,0^{\circ} \mathrm{C}$ dan $29,7^{\circ} \mathrm{C}$. Ketebalan lapisan permukaan antara 50-100 m, sedangkan lapisan termoklin sekitar $250 \mathrm{~m}$. Massa air bersuhu tinggi berada di dekat pantai bagian timur sedangkan massa air bersuhu rendah berada di lepas pantai. Salinitas permukaan perairan berkisar antara 33,19 dan 34,67. Massa air bersalinitas tinggi berada di lepas pantai sedangkan massa air bersalinitas rendah berada di dekat pantai. Sebaran suhu dan salinitas di lapisan permukaan lebih kompleks dibanding pada lapisan yang lebih dalam. 


\section{DAFTAR PUSTAKA}

Fong, D.A. dan W.R. Geyer. 2001. Response of a river plume during an upwelling favorable wind event. Journal of Geophysical Research-Oceans 106(C1): 1067-1084.

Garrison, T. 2004. Essentials of oceanography. Brooks/Cole, Australia, 352 pp.

Geyer, W.R. 1997. Influence of wind on dynamics and flushing of shallow estuaries. Estuarine, Coastal and Shelf Science 44(6): 713 $\square 722$.

Geyer, W.R., P. Hill, T. Milligan dan P. Traykovski. 2000. The structure of the Eel River plume during floods. Continental Shelf Research 20(16): 2067-2093.

Geyer, W.R. dan R.P. Signell. 1992. A Reassessment of the role of tidal dispersion in estuaries and bays. Estuaries 15(2): 97-108.

Hickey, B.M., L.J. Pietrafesa, D.A. Jay dan W.C. Boicourt. 1998. The Columbia River plume study: Subtidal variability in the velocity and salinity fields. Journal of Geophysical Research 103(C5): 10,339-10,368.

Kalangi, P.N.I. 2008. Struktur salinitas di perairan pantai muara Sungai Sario Manado. Pacific Journal 3(2): 195 199.

Kalangi, P.N.I., K.W.A. Masengi, M. Iwata, F.P.T. Pangalila dan I.F. Mandagi. 2012. Profil salinitas dan suhu di Teluk Manado pada hari-hari hujan dan tidak hujan. Jurnal Perikanan dan Kelautan Tropis VIII(3): 90-93.
Kitoh, A. 2001. Effect of orography on land and ocean surface temperature. In: T. Matsuno dan H. Kida (Editors), 14th Toyota Conference. Present and future of modeling global environment change: toward integrated modeling. Terrapub, Mikkabi, Shizuoka, Japan, pp. 427-431.

Knauss, J.A. 1997. Introduction to physical oceanography. Prentice Hall, Upper Sadle River, 309 pp.

Laevastu, T. dan M.L. Hayes. 1982. Fisheries oceanography and ecology. Fishing News Books, Farnham, 199 pp.

Lewis, R. 1997. Dispersion in estuaries and coastal waters. John Wiley and Sons, Chichester, 312 pp.

Nontji, A. 1987. Laut Nusantara. Djambatan, Jakarta $\$ 68$ pp.

Tulungen, D., P.N.I. Kalangi dan W. Patty. 2012 Kajiantpola arus di daerah penangkapan bagan apung di Desa Tateli Weru. Jurnal Ilmu dan Teknologi Perikanan Tangkap 1(2): 27-32.

van de Kreeke, J. dan K. Robaczewska. 1989. Effect of wind on the vertical circulation and stratification in the Volkerak estuary. Netherland Journal of Sea Research 23(3): 239-253.

Xie, S.-P., J. Hafner, Y. Tanimeto, W.T. Liu, H. Tokinaga dan H. Xu. 2002. Bathymetric) effect on the winter sea surface temperature and climate of the Yellow and East China Seas. Geophysical Research Letters 29(24): 2228, doi:10.1029/2902GL015884.

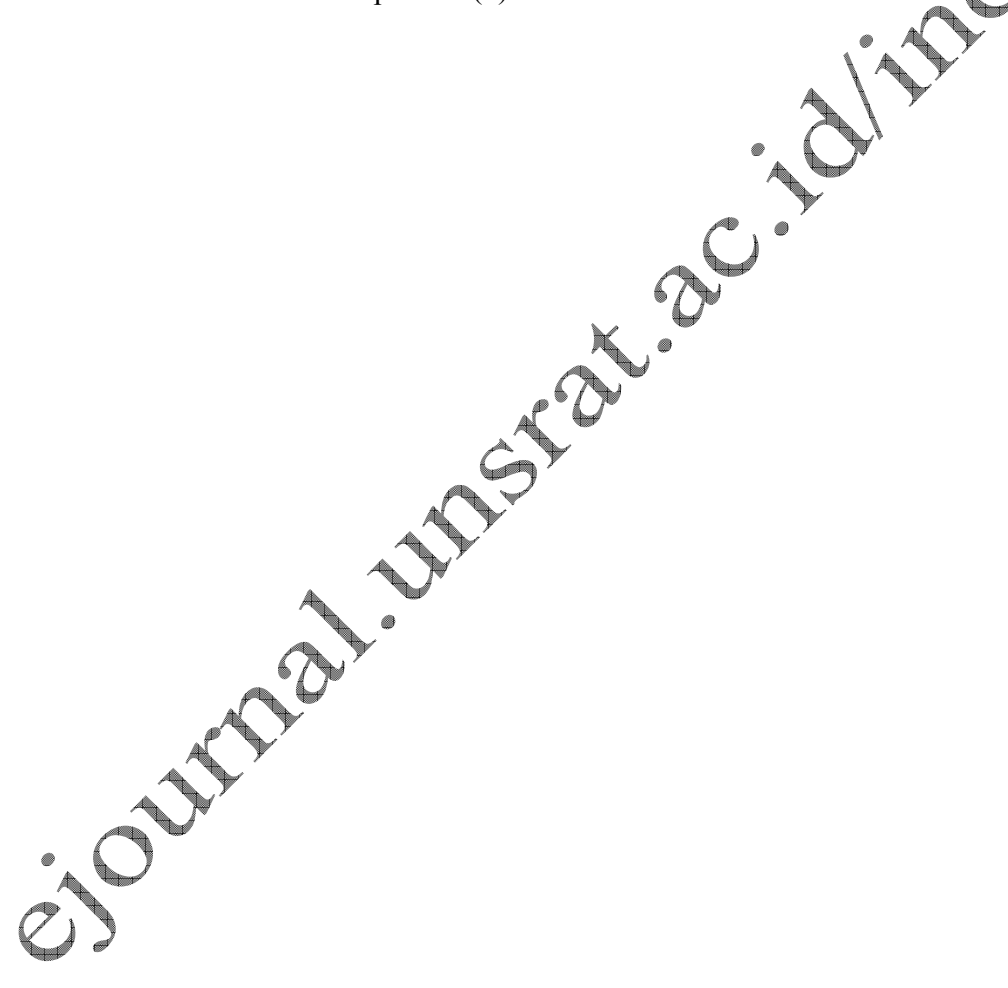

